\title{
ANALISIS PENERAPAN AKUNTANSI PERPAJAKAN TERHADAP DEPRESIASI ASET SEWA GUNA USAHA DENGAN HAK OPSI DITINJAU DARI SUDUT PANDANG PENYEWA PADA PT. SINAR CIPTA PERSADA SEJATI
}

\author{
Azarya Anugrah Toweula ${ }^{1}$, Jantje J. Tinangon ${ }^{2}$, Meily Kalalo ${ }^{3}$ \\ 1,2,3 Jurusan Akuntansi, Fakultas Ekonomi dan Bisnis, Universitas Sam Ratulangi, Jl. Kampus Bahu, Manado, \\ 95115, Indonesia
}

E-mail : azarya.toweula@yahoo.com

\begin{abstract}
A lease is a financing activity in the form of the provision of capital goods either under a lease with a finance lease or an operating lease for use by the lessee for a specified period of time on a periodic basis. Lease do it by PT. Sinar Cipta Persada Sejati is lease with Capital Lease method. At the end of lease period, the company has authorities to buy lease asset. The purpose of this research is to know how the implementation of tax accounting to capital lease asset depreciation at PT. Sinar Cipta Persada Sejati as Lessee. This research use descriptive comparative method. The results of this research has proven that transaction of capital lease do it by PT. Sinar Cipta Persada Sejati has not applicable with tax rules, in depreciation problem the company only applied the commercial accounting rules, that is depreciation starts when the company get the capital lease asset and the basic of depreciation is the cost of the asset. The difference of commercial accounting anda tax accounting will be a fiscal correction of income taxes.
\end{abstract}

Keywords: Tax Accounting, Lease, Capital Lease

\section{PENDAHULUAN}

Perusahaan biasanya melakukan beberapa alternatif pembiayaan dalam hal pengadaan barang modal. Pembiayaan yang berasal dari sumber internal dan dari sumber eksternal. Pembiayaan yang berasal dari sumber internal adalah yang berasal dari perusahaan itu sendiri, seperti modal saham, laba ditahan, dan lain-lain. Pembiayaan yang didapat dari sumber eksternal yaitu dari luar perusahaan, diantaranya sewa guna usaha (leasing), pinjaman bank, dan lain-lain. Untuk badan usaha atau perusahaan yang memiliki modal besar, biasanya akan menggunakan modal dari perusahaan itu sendiri, tetapi sebaliknya perusahaan atau badan usaha yang tidak memiliki modal besar, akan memilih alternatif pembiayaan dari luar perusahaan. Salah satu jenis pembiayaan yang mulai digunakan perusahaan di Indonesia dalam pengadaan barang modal adalah pembiayaan melalui kegiatan sewa guna usaha (leasing).

Di Indonesia, Sewa Guna Usaha lebih dikenal dengan sebutan leasing. Sewa guna usaha (leasing) merupakan aktivitas pembiayaan dalam hal pengadaan barang modal yang akan digunakan oleh lessee selama beberapa periode berdasarkan pembayaran secara berkala, dengan cara sewa guna usaha dengan hak opsi (finance lease) ataupun sewa guna usaha tanpa hak opsi (operating lease). Seperti yang diatur dalam Keputusan Menteri Keuangan No. 1169/KMK.01/1991 tentang Kegiatan Sewa Guna Usaha (leasing), sewa guna usaha dengan hak opsi (capital lease) yaitu, transaksi sewa guna usaha dimana lessor berlaku sebagai pihak yang mendanai barang modal dan lessee secara teratur melakukan pembayaran atas transaksi sewa guna usaha kepada lessor dimana pada akhir periode sewa lessee memiliki hak opsi untuk membeli barang modal sewa guna usaha. Opsi untuk membeli dilakukan dengan melunasi pembayaran nilai sisa barang modal sewa guna usaha. 


\section{TINJAUAN PUSTAKA}

Konsep Akuntansi. Menurut Suwardjono (2014), akuntansi adalah kegiatan untuk mencatat, menggolongkan, dan meringkas peristiwa dan transaksi dalam bentuk keuangan dengan cara yang memiliki daya guna dan dalam bentuk satuan uang, dan menjelaskan hasil proses tersebut.

Konsep Akuntansi Perpajakan. Supriyanto (2011), akuntansi perpajakan merupakan suatu proses untuk mencatat, menggolongkan, dan mengikhtisaran suatu transaksi atau peristiwa keuangan yang berkaitan dengan perpajakan dan dilanjutkan dengan menyusun laporan keuangan fiskal yang disusun menurut peraturan dan ketetapan perpajakan yang berlaku sebagai acuan untuk pembuatan Surat Pemberitahuan Tahunan.

Fungsi Akuntansi Perpajakan. Fungsi akuntansi menurut Muljono (2011) yaitu, mengolah data kuantitatif dalam bentuk keuangan dan akan digunakan untuk pengambilan keputusan. Oleh karena itu, akuntansi harus dapat memenuhi tujuan kualitatif.

Konsep Pajak. Menurut Undang-Undang Republik Indonesia Nomor 28 Tahun 2007 Tentang Perubahan Ketiga Atas Undang-Undang Nomor 6 Tahun 1983 Tentang Ketentuan Umum Dan Tata Cara Perpajakan, pajak merupakan kontribusi untuk negara dari wajib pajak yang terutang oleh badan atau orang pribadi yang sifatnya memaksa menurut UndangUndang, dengan tidak menerima atau merasakan manfaatnya secara langsung dan dipergunakan untuk kepentingan negara bagi sepenuhnya kesejahteraan rakyat.

Fungsi Pajak. Menurut Mardiasmo (2018), fungsi pajak ada dua, yaitu:

1.Fungsi Budgetair (penerimaan). Sebagai awal atau sumber dalam menghasilkan dana secara maksimal kedalam kas negara dan tujuannya untuk menopang keperluan negara, yaitu pembangunan dan pengeluaran lainnya.

2.Fungsi Regulerend (mengatur). Sebagai alat yang digunakan untuk menggapai tujuan khusus dalam bidang keuangan. Pemerintah mengatur pertumbuhan ekonomi melalui kebijaksanaan pajak.

Sewa Guna Usaha (Leasing). Di Indonesia, pada tahun 1974 sewa guna usaha (leasing) diperkenalkan dengan dikeluarkannya Surat Keputusan Bersama Menteri Keuangan, Menteri Perindustrian dan Perdagangan No. Kep-122/MK/2/1974 dan No. 30/KPB/1/74 tanggal 7 Februari 1974 tentang "Perizinan Usaha Leasing". Menurut Surat Keputusan Bersama tersebut menyatakan:

"Leasing adalah kegiatan pembiayaan perusahaan dalam bentuk penyediaan barang-barang modal untuk digunakan oleh suatu perusahaan dalam jangka waktu tertentu berdasarkan pembayaran-pembayaran secara berkala disertai dengan hak opsi bagi perusahaan yang menyewa untuk membeli barang-barang modal yang bersangkutan atau memperpanjang jangka waktu leasing berdasarkan nilai sisa yang telah disepakati bersama”.

Jenis-jenis Sewa Guna Usaha (Leasing). Dalam PSAK No. 30 (revisi 2015) kegiatan sewa guna usaha dibedakan dalam 2 jenis, yaitu sewa guna usaha dengan hak opsi (capital lease) dan sewa guna usaha tanpa hak opsi (operating lease).

1. Sewa guna usaha dengan hak opsi/sewa pembiayaan (capital/finance lease). Menurut Waluyo (2014), sewa pembiayaan merupakan sewa yang seluruh manfaat dan risiko yang menyangkut dengan kepemilikan suatu aset dialihkan secara substansial.

2. Sewa Guna Usaha tanpa Hak Opsi/sewa operasi (operating lease). Menurut PSAK No. 30 (revisi 2015), sewa operasi adalah adalah sewa yang tidak mengalihkan secara substansial seluruh risiko dan manfaat yang terkait dengan kepemilikan aset.

Perlakuan Akuntansi oleh Penyewa Guna Usaha (lessee)

1. Berdasarkan prinsip-prinsip akuntansi komersial.

2. Berdasarkan peraturan perpajakan 
Kriteria Penggolongan Sewa Pembiayaan (Sewa Guna Usaha dengan Hak Opsi).

Kriteria yang harus dipenuhi lessee agar dianggap sebagai sewa pembiayaan (capital lease) menurut FASB Statement No. 13 adalah sebagai berikut:

1. Lessor akan memudahkan hak kepemilikan aset pada lessee yaitu pada akhir periode sewa guna usaha berakhir.

2. Dalam kontrak sewa guna usaha mempunyai alternatif membeli atau tidak membeli.

3. Jangka waktu sewa guna usaha $75 \%$ atau lebih dan pada taksiran umur ekonomi dari aset sewa guna usaha dan permulaan masa sewa tidak dimulai pada sisa $25 \%$ dari umur ekonomis aset sewa guna usaha.

4. Nilai sekarang (present value) dari pembayaran sewa pada permulaan sewa guna usaha harus minimal sama atau lebih besar dari $90 \%$ atau lebih dari nilai pasar wajar bagi lessor setelah dikurangkan kredit investasi (excecutor cost, yaitu biaya pemeliharaan, asuransi, dan pajak) yang ditahan lessor.

Laporan Keuangan. Ikatan Akuntan Indonesia (PSAK No. 1, revisi 2007) laporan keuangan adalah suatu penyajian posisi keuangan dan kinerja keuangan suatu entitas yang disusun secara terstruktur.

Laporan Keuangan Komersial. Menurut Waluyo (2014), tujuan pokok laporan keuangan komersial adalah secara wajar melaporkan atau menunjukkan keadaan dari posisi keuangan suatu perusahaan sebagai entitas.

Laporan Keuangan Fiskal. Menurut Suandy (2016) laporan keuangan fiskal adalah laporan keuangan yang digunakan untuk keperluan penghitungan pajak dan disusun menurut peraturan perpajakan.

Konsep Aset. Dalam PSAK No. 16 (revisi 2015), aset adalah aset berwujud yang mempunyai masa manfaat lebih dari satu tahun yang diperoleh dalam bentuk siap pakai, dan dimaksudkan untuk tidak dijual dan digunakan dalam rangka kegiatan operasi perusahaan.

Pengertian Aktiva Tetap. Menurut Ikatan Akuntan Indonesia (PSAK 16, revisi 2015), aset tetap adalah aset berwujud yang diperoleh untuk dipakai dalam proses produksi dan juga dipakai dalam penyediaan barang dan jasa untuk disewakan ke pihak lain, dan bisa digunakan dalam jangka waktu lebih dari satu periode.

Bentuk-bentuk Aktiva Tetap. Secara umum aktiva tetap diklasifikasikan ke dalam dua golongan, yaitu:

1. Aktiva tetap berwujud. Aktiva tetap berwujud adalah harta yang dimiliki perusahaan yang ada secara fisik dan memiliki masa manfaat yang relatif permanen (dapat digunakan berkali-kali dan dalam jangka waktu yang lama) yang digunakan dalam kegiatan operasional perusahaan.

2. Aktiva tetap tidak berwujud. Aktiva tetap tidak berwujud merupakan aktiva jangka panjang tetapi tidak berbentuk fisik yang tidak untuk dijual dan bermanfaat bagi perusahaan. Aktiva tidak berwujud antara lain adalah hak cipta, hak paten, merek dagang, dan lain-lain.

Penyusutan Aktiva Tetap. Penyusutan atau depresiasi merupakan konsep alokasi harga perolehan harta tetap berwujud.

Kriteria Aset yang dapat disusutkan

1. Menurut akuntansi komersial. Menurut Ikatan Akuntan Indonesia (PSAK 16, revisi 2015) yang dikutip Waluyo (2011:350) aset yang bisa disusutkan, yaitu aset yang: (a) bisa untuk dipakai selama beberapa periode; (b) masa manfaatnya terbatas; dan (c) dikuasai perusahaan yang dipakai dalam proses produksi atau penyediaan barang dan jasa, untuk disewakan atau untuk memenuhi tujuan administratif.

2. Menurut ketentuan perpajakan. Syarat aset tetap yang bisa disusutkan menurut ketentuan perpajakan (Waluyo, 2011:172) adalah : (a) aset tetap yang bisa disusutkan adalah aset 
yang berwujud; (b) aset tetap yang manfaatnya lebih dari 1 (satu) tahun; dan (c) aset tetap tersebut dapat dipakai untuk menuntut, memelihara, dan mendapatkan penghasilan.

\section{Metode Penyusutan Menurut Akuntansi Komersial}

1. Metode Garis Lurus

2. Metode Saldo Menurun

3. Metode Saldo Menurun Berganda

4. Metode Jumlah Angka Tahun

5. Metode Jumlah Unit Produksi

Metode Penyusutan dan Tarif Penyusutan Fiskal. Metode penyusutan yang bisa digunakan berdasarkan ketentuan perpajakan yang berlaku saat ini adalah : (1) metode garis lurus (straight line); dan (2) metode saldo menurun (declining balance).

\section{METODE PENELITIAN}

Jenis Penelitian. Penelitian ini menggunakan jenis penelitian kualitatif dengan pendekatan deskriptif komparatif.

Tempat dan Waktu Penelitian. Penelitian ini dilakukan di PT. Sinar Cipta Persada Sejati. Perusahaan ini terletak di Jln. Martadinata No. 32 Kelurahan Dendengan Luar, Kecamatan Paal 2, kota Manado, Sulawesi Utara.

\section{Jenis Data}

1. Data Kuantitatif. Data yang berisi bilangan ataupun angka yang dipakai untuk mendeskripsikan bermacam gambaran dan kejadian yang terjadi berhubungan dengan pelaksanaan penelitian.

2. Data Kualitatif. Data kualitatif merupakan data dalam bentuk deskriptif atau kata-kata yang menyangkut tangapan responden.

Dalam penelitian ini, penulis menggunakan data kualitatif yaitu data-data yang diperoleh dari wawancara tentang transaksi sewa guna usaha yang dilakukan perusahaan dan data kuantitatif seperti daftar transaksi lease, daftar aset dan penyusutannya, dan laporan keuangan perusahaan sebagai dasar untuk menganalisis bagaimana penerapan akuntansi perpajakan terhadap depresiasi aset sewa guna usaha dengan hak opsi pada PT. Sinar Cipta Persada Sejati.

\section{Sumber Data}

1. Data primer. Sumber data primer merupakan sumber data yang secara langsung memberikan data kepada pengumpul data (Sugiyono, 2013).

2. Data sekunder. Sumber data sekunder adalah sumber data yang berisi hasil pengolahan lanjutan dari data primer yang dibuat dalam bentuk berbeda (Sugiyono, 2013).

Dalam penelitian ini penulis menggunakan sumber data primer, yaitu data hasil wawancara tentang transaksi sewa guna usaha PT. Sinar Cipta Persada Sejati yang dilakukan kepada Bagian Administrasi Keuangan dan Bagian Akuntansi Perpajakan secara langsung.

\section{Metode Pengumpulan Data}

1. Teknik wawancara. Memberikan pertanyaan secara langsung kepada responden dari perusahaan atau pihak yang terkait. Tujuan metode ini adalah untuk memperoleh data tentang gambaran umum perusahaan mengenai penerapan akuntansi perpajakan terhadap aset sewa guna usaha dengan hak opsi pada PT. Sinar Cipta Persada Sejati.

2. Teknik dokumentasi. Teknik ini digunakan untuk mengetahui perlakuan perusahaan mengenai penerapan akuntansi perpajakan terhadap aset sewa guna usaha dengan hak opsi pada PT. Sinar Cipta Persada Sejati.

3. Teknik kepustakaan. Pengumpulan data dengan mencari literatur dan laporan-laporan yang berhubungan dengan transaksi sewa guna usaha. 
Metode dan Proses Analisis. Metode analisis data yang digunakan penulis dalam penelitian ini adalah analisis data deskriptif komparatif. Di dalam penelitian ini, penulis mempelajari laporan keuangan dari perusahaan dan juga menganalisis penerapan akuntansi perpajakan terhadap depresiasi aset sewa guna usaha dengan hak opsi pada PT. Sinar Cipta Persada Sejati yang bertindak sebagai penyewa (lessee). Dalam hal ini aset sewa guna usaha yang dimaksud adalah mesin Asphalt Mixing Plant.

\section{HASIL PENELITIAN DAN PEMBAHASAN}

\subsection{Hasil Penelitian}

Transaksi Sewa Guna Usaha PT. Sinar Cipta Persada Sejati. Sebagaimana telah diuraikan sebelumnya bahwa pada tahun 2011 perusahaan mengembangkan usahanya yakni produksi dan penjualan aspal campuran (asphalt mixing) yang digunakan dalam proyekproyek pengaspalan jalan. Untuk menjalankan usaha ini perusahaan membeli 1 unit mesin Asphalt Mixing Plant yang diperoleh dengan menggunakan jasa leasing. Sewa guna usaha yang dilakukan oleh PT. Sinar Cipta Persada Sejati adalah sewa guna usaha dengan hak opsi/sewa pembiayaan (capital lease). Sehingga pada akhir masa sewa, perusahaan memiliki hak untuk membeli aktiva tersebut. Proses transaksi sewa guna usaha dilakukan sebagai berikut :

- PT. Sinar Cipta Persada Sejati (lessee) mengajukan permohonan dan persetujuan pembelian mesin Asphalt Mixing Process kepada penjual PT. Melu Bangun Wiweka dengan harga yang disepakati yang dituangkan dalam kontrak.

- Setelah mendapat persetujuan dari pihak penjual maka PT. Sinar Cipta Persada Sejati mengajukan permohonan dan persetujuan pembiayaan dalam bentuk sewa guna usaha kepada PT. Indomobil Finance (lessor) dengan jumlah dan syarat-syarat yang disepakati bersama dan dituangkan dalam kontrak sewa guna usaha.

- Setelah ketiga pihak sepakat maka PT. Indomobil Finance (lessor) menyetor sejumlah uang yang telah disepakati kepada PT. Melu Bangun Wiweka atas nama PT. Sinar Cipta Persada Sejati (lessee). Selanjutnya PT. Melu Bangun Wiweka (penjual) menyerahkan peralatan mesin Asphalt Mixing Process kepada PT. Sinar Cipta Persada Sejati.

- Selanjutnya PT. Sinar Cipta Persada Sejati (lessee) akan membayar angsuran sewa kepada PT. Indomobil Finance sesuai kontrak sewa yang telah disepakati.

Berikut ini penulis sajikan data transaksi sewa guna usaha yang dilaksanakan pada tanggal 26 Mei 2011 dengan kesepakatan sebagai berikut:

Tabel 1. Data Transaksi Sewa Guna Usaha PT. Sinar Cipta Persada Sejati

\begin{tabular}{|c|c|c|}
\hline $\begin{array}{l}\text { Jenis Aset Sewa } \\
\text { Guna Usaha }\end{array}$ & $\begin{array}{l}\text { Asphalt Mixing } \\
\text { Plant }\end{array}$ & $\begin{array}{l}\text { Model AMP-MBW-1000/FA, kapasitas } 60-80 \text { ton } \\
\text { / jam }\end{array}$ \\
\hline Harga perolehan & $\begin{array}{l}\text { Rp. } \\
5.476 .517 .603,-\end{array}$ & \\
\hline Nilai sewa & $\begin{array}{l}\text { Rp. } \\
5.000 .000 .000,-\end{array}$ & \\
\hline Selisih & $\begin{array}{l}\text { Rp. } \\
476.517 .603,-\end{array}$ & $\begin{array}{l}\text { Selisih ini merupakan uang muka yang harus } \\
\text { dibayar PT. Sinar Cipta Persada Sejati kepada PT. } \\
\text { MBW selaku penjual. }\end{array}$ \\
\hline Masa sewa & 5 tahun & \\
\hline Bunga lease & $8,5 \% /$ tahun & Bunga tetap \\
\hline Umur ekonomis & 5 tahun & Aspek teknis PT. MBW \\
\hline
\end{tabular}


Dapat dilihat dari data transaksi sewa guna usaha dengan hak opsi yang dilakukan oleh PT. Sinar Cipta Persada Sejati, jenis aset yang disewa guna usaha adalah 1 (satu) unit mesin Asphalt Mixing Plant dengan harga perolehan sebesar Rp. 5.476.517.603,- yang terdiri dari nilai sewa sebesar Rp. 5.000.000.000,- dan selisih yang merupakan uang muka yang harus dibayar PT. Sinar Cipta Persada Sejati kepada penjual sebesar Rp. 476.517.603,--. Masa sewa guna usaha yang dilakukan untuk mesin Asphalt Mixing Plant ini adalah 5 tahun, dengan bunga lease 8,5\% per tahun dan umur ekonomis yang ditentukan oleh penjual adalah 5 tahun. Nilai residual (nilai sisa) 10\%, yaitu sebesar Rp.547.651.760,-

\subsection{Pembahasan}

Analisa Kriteria Sewa Guna Usaha. Keputusan Menteri Keuangan Nomor 1169/KMK.01/1991 tanggal 27 November 1991, maka kegiatan sewa guna usaha diklasifikasikan sebagai sewa guna usaha dengan hak opsi jika semua kriteria berikut terpenuhi:

Kriteria 1:

Jumlah pembayaran angsuran selama 5 tahun:

$\begin{array}{ll}\text { Rp. } 102.582 .656,64 \text { x } 60 \text { bulan } & =R p .6 .154 .959 .398,12 \\ \text { Nilai sisa barang modal } & =R \text { R. } 547.651 .760,00 \\ \text { Jumlah } & =\text { Rp. } 6.702 .611 .158,12\end{array}$

Harga perolehan barang modal + keuntungan (bunga) :

Rp. 5.000.000.000 + Rp. 1.154.959.398,12 = Rp. 6. 154.959.398,12

Dapat dilihat bahwa jumlah angsuran yang dibayarkan ditambah dengan nilai sisa barang modal dapat menutupi harga perolehan barang modal ditambah keuntungan (bunga) lessor, maka tranksaksi yang dilakukan oleh PT. Sinar Cipta Persada Sejati ini memenuhi kriteria 1 dan dapat dikategorikan sebagai sewa pembiayaan (capital lease).

Kriteria 2:

Berdasarkan Keputusan Menteri Keuangan Nomor 1169/KMK.01/1991 tentang Kegiatan Sewa Guna Usaha, bahwa Mesin Asphalt Mixing Plant digolongkan sebagai barang modal golongan II. Dalam keputusan tersebut ditetapkan masa sewa guna usaha sekurangkurangnya adalah 2 (dua) tahun. Masa sewa guna usaha yang dilakukan PT. Sinar Cipta Persada Sejati adalah 60 bulan (5 tahun), maka kriteria kedua sebagai sewa pembiayaan terpenuhi.

Kriteria 3

Menurut pejanjian sewa guna usaha, pada akhir masa sewa lessee memiliki hak untuk membeli aktiva tersebut, maka kriteria ketiga sebagai sewa pembiayaan terpenuhi.

Kesimpulan Akhir :

Semua kriteria menurut ketentuan perpajakan yang berlaku mengenai kriteria penggolongan sewa guna usaha telah terpenuhi, maka transaksi sewa guna usaha atas 1 (satu) unit Mesin Asphalt Mixing Plant dapat digolongkan sebagai sewa pembiayaan.

Akuntansi Penyusutan Aset Sewa Guna Usaha Menurut Peraturan Perpajakan. Sesuai Keputusan Menteri Keuangan No. 1169/KMK.01/1991, dalam transaksi sewa guna usaha dengan hak opsi/sewa pembiayaan (capital lease) lessee memiliki hak untuk membeli aktiva sewa guna usaha sebesar nilai sisanya pada akhir masa sewa. Berdasarkan ketentuan tersebut, maka PT. Sinar Cipta Persada Sejati diperkenankan untuk melakukan penyusutan atas Mesin Asphalt Mixing Plant setelah dilakukan hak untuk membeli mesin tersebut. Dalam transaksi sewa guna usaha yang dilakukan oleh PT. Sinar Cipta Persada Sejati, perusahaan yang bertindak sebagai lessee menggunakan hak opsinya untuk membeli mesin Asphalt Mixing Plant tersebut, maka penyusutan dilakukan berdasarkan nilai residual aktiva tersebut, yaitu sebesar Rp. 547.651.760,-. Sesuai dengan ketentuan perpajakan, umur ekonomis yang digunakan PT. Sinar Cipta Persada Sejati untuk menyusutkan aktiva tersebut adalah 8 
(delapan) tahun. Untuk metode penyusutan PT. Sinar Cipta Persada Sejati menggunakan metode garis lurus (straight-line method). Perhitungan tersebut penulis sajikan dalam tabel berikut :

Tabel 2. Penyusutan 1 (satu) unit Asphalt Mixing Plant menurut peraturan Perpajakan

\begin{tabular}{llccc}
\hline Tahun & $\begin{array}{c}\text { Harga } \\
\text { Perolehan } \\
(\mathbf{R p})\end{array}$ & $\begin{array}{c}\text { Biaya } \\
\text { Penyusutan } \\
(\mathbf{R p})\end{array}$ & $\begin{array}{c}\text { Akumulasi } \\
\text { Penyusutan } \\
(\mathbf{R p})\end{array}$ & $\begin{array}{c}\text { Nilai } \\
\text { Sisa Buku } \\
(\mathbf{R p})\end{array}$ \\
\hline Juni 2016 & 547.651 .760 & 39.932 .941 & 39.932 .941 & 507.718 .819 \\
$\mathbf{2 0 1 7}$ & $547,651,760$ & $68,456,470$ & $108,389,411$ & $439,262,349$ \\
$\mathbf{2 0 1 8}$ & $547,651,760$ & $68,456,470$ & $176,845,881$ & $370,805,879$ \\
$\mathbf{2 0 1 9}$ & $547,651,760$ & $68,456,470$ & $245,302,351$ & $302,349,409$ \\
$\mathbf{2 0 2 0}$ & $547,651,760$ & $68,456,470$ & $313,758,821$ & $233,892,939$ \\
$\mathbf{2 0 2 1}$ & $547,651,760$ & $68,456,470$ & $382,215,291$ & $165,436,469$ \\
$\mathbf{2 0 2 2}$ & $547,651,760$ & $68,456,470$ & $450,671,761$ & $96,979,999$ \\
$\mathbf{2 0 2 3}$ & $547,651,760$ & $68,456,470$ & $519,128,231$ & $28,523,529$ \\
$\mathbf{2 0 2 4}$ & $547,651,760$ & $28,523,529$ & $547,651,760$ & \\
\hline
\end{tabular}

Sumber: Data Olahan (2018)

Perbedaan perlakuan antara kebijakan akuntansi komersial dan ketentuan perpajakan ini akan berdampak pada Pajak Penghasilan terhutang PT. Sinar Cipta Persada Sejati. Pajak Penghasilan terhutang PT. Sinar Cipta Persada Sejati akan mengalami koreksi fiskal positif dan koreksi fiskal negatif selama tahun 2011-2024. Koreksi positif terjadi jika biaya penyusutan yang dihitung menurut akuntansi perpajakan lebih kecil daripada biaya penyusutan menurut akuntansi komersial, sehingga akan menyebabkan laba fiskal sebelum pajak menjadi lebih besar sehingga Pajak Penghasilan PT. Sinar Cipta Persada Sejati yang terhutang juga menjadi besar. Sedangkan koreksi negatif terjadi jika biaya penyusutan yang dihitung menurut akuntansi perpajakan lebih besar daripada biaya penyusutan menurut akuntansi komersial, sehingga akan menyebabkan laba fiskal sebelum pajak menjadi lebih kecil.

\section{KESIMPULAN DAN SARAN}

\subsection{Kesimpulan}

Berdasarkan perhitungan dan analisis yang telah dijelaskan maka kesimpulan penelitian ini adalah sebagai berikut:

1. Berdasarkan kriteria lease maka kegiatan sewa guna usaha yang dilakukan PT. Sinar Cipta Persada Sejati memenuhi kriteria Sewa Guna Usaha Dengan Hak Opsi (capital/finance lease).

2. Transaksi sewa guna usaha dengan hak opsi (capital/finance lease) yang dilakukan PT. Sinar Cipta Persada Sejati belum sepenuhnya menerapkan peraturan perpajakan.

3. Penyusutan aset sewa guna usaha, PT. Sinar Cipta Persada Sejati menerapkan peraturan berdasarkan akuntansi komersial saja. PT. Sinar Cipta Persada Sejati mengakui penyusutan atas aktiva sewa guna usaha setelah aktiva tersebut diperoleh dengan nilai perolehan sebagai dasar penyusutan.

4. Menurut ketentuan perpajakan, PT. Sinar Cipta Persada Sejati bisa melakukan penyusutan setelah hak opsi digunakan dan penyusutannya dihitung berdasarkan nilai opsi/nilai residual.

5. Perbedaan antara akuntansi komersial dan akuntansi perpajakan tersebut menyebabkan adanya koreksi fiskal atas Pajak Penghasilan PT. Sinar Cipta Persada Sejati.

6. Atas koreksi fiskal yang terjadi maka PPh terhutang perusahaan adalah sebesar Rp. 1.291.818.670,-. Hal ini sudah sesuai dengan peraturan perpajakan yang berlaku. 


\subsection{Saran}

Saran yang dapat penulis berikan kepada PT. Sinar Cipta Persada Sejati sehubungan dengan transaksi Sewa Guna Usaha dengan hak opsi (capital lease) yang dilakukan PT. Sinar Cipta Persada Sejati sebagai berikut:

1. Sebaiknya dalam menghitung penyusutan aktiva tetap yang diperoleh dari transaksi sewa guna usaha perusahaan menggunakan ketentuan perpajakan yang telah diatur. Sehingga penyusutan untuk aktiva sewa guna usaha tetap sesuai dengan ketentuan yang berlaku.

2. Alangkah baiknya perusahaan selalu memperhatikan dan mengikuti peraturan perpajakan yang berlaku sehubungan dengan transaksi sewa guna usaha dengan hak opsi (capital lease).

\section{DAFTAR PUSTAKA}

Aryani, Susi. 2011. Penerapan Akuntansi Pajak Atas Kepemilikan Aktiva Tetap Berupa Kendaraan Dan Software Dengan Metode Capital Lease Pada PT. Alandick Indonesia Sebagai Lessee. Universitas Mercu Buana. Jakarta.

Banteng, Djayanti. Astri, 2013. Analisis Pengakuan Piutang Tak Tertagih dan Penyajian Laporan Keuangan pada PT. Bank Sulut. Skripsi, Fakultas Ekonomi UNSRAT. Manado.

Financial Accounting Standards Board (FASB). 1980. Statement of Financial Accounting Concepts No. 13: Accounting For Leases. Norwalk. Connecticut.

Ikatan Akuntan Indonesia. 2012. Pernyataan Standar Akuntansi Keuangan. Edisi PSAK 30. Revisi 2015. Salemba Empat. Jakarta.

Mardiasmo. 2018. Perpajakan-Edisi Terbaru 2018. Edisi XIX. Andi. Yogyakarta.

Suwardjono. 2014. Akuntansi Pengantar Bagian 1, Edisi Ketiga. BPFE. Yogyakarta.

Suandy, Erly. 2016. Perencanaan Pajak. Edisi Enam. Salemba Empat. Jakarta.

Sugiyono. 2013. Metode Penelitian Kuantitatif, Kualitatif dan R\&D. Alfabeta, CV. Bandung. Supriyanto, Eddy. 2011. Akuntansi Perpajakan. Edisi Pertama. Graha Ilmu. Yogyakarta.

Surat Keputusan Bersama Menteri Perindustrian, Menteri Keuangan dan Perdagangan No. Kep-122/MK/2/1974 dan No. 30/KPB/I/74 tentang Perizinan Usaha Leasing.

Surat Keputusan Menteri Keuangan Nomor 1169/KMK.01/1991 Tentang Kegiatan Sewa Guna Usaha (Leasing).

Waluyo. 2014. Akuntansi Pajak. Edisi 5. Salemba Empat. Jakarta. 